\title{
MicroRNA control of invasion and metastasis pathways
}

\author{
Rahul Sreekumar, Berna S. Sayan, Alex H. Mirnezami and A. Emre Sayan*
}

Cancer Sciences Division, Cancer Research UK Centre, University of Southampton, Southampton, UK

Edited by:

Gerry Melino, Medical Research

Council, UK

Reviewed by:

Gerry Melino, Medical Research Council, UK

*Correspondence:

A. Emre Sayan, Cancer Sciences

Division, University of Southampton,

Somers Cancer Research Building,

Tremona Road, Southampton,

MP824, SO16 6YD, UK

e-mail: a.e.sayan@soton.ac.uk
Despite recent advances, cancer remains a leading cause of death worldwide. In developed countries, the incidence of colorectal and breast cancer has been stable, but no improvement in prognosis has been observed if the patient presents with metastases at diagnosis. This fact highlights the importance of therapeutic approaches targeting cellular invasion and metastasis programs as the next step in cancer treatment. During carcinoma progression a process called epithelial-mesenchymal transition (EMT) results in enhanced invasion and motility which is directly linked with loss of epithelial polarity and epithelial junctions, migration permissive cytoskeleton alterations, and the acquisition of mesenchymal properties. The recent discovery of microRNAs (miRNAs) controlling key cellular pathways has opened a new era in understanding how EMT pathways are modulated. In this review, we classify EMT regulating proteins according to their cellular localization (membrane, cytoplasmic, and nuclear), and summarize the current knowledge on how they are controlled by miRNAs and propose potential miRNAs for the transcripts that may control their expression.

Keywords: microRNA, EMT, metastasis, invasion, prognosis

\section{INTRODUCTION}

Despite advances in diagnosis and treatment, cancer remains the second highest cause of death in developing countries (Jemal et al., 2011). The vast burden of cancer associated morbidity and mortality is principally attributable to the development of metastases from the primary tumor site through a complicated and multistep process whereby cancer cells depart their normal microenvironment, and disseminate and colonize distant organs. Even so, the cellular and molecular machinery underlying metastasis is relatively poorly understood, and more effective therapeutic strategies are clearly required in order to oppose cancer dissemination.

Cellular invasion and epithelial-mesenchymal transition (EMT) programs enable metastasis. EMT is an embryologically conserved genetic program by which epithelial cells down regulate intercellular tight junctions, loose polarity, express mesenchymal markers, and manifest a migratory phenotype (Thiery and Sleeman, 2006). While the significance of EMT in gastrulation and neural crest cell migration during embryogenesis is wellestablished, its role in tumor progression and metastasis is still under investigation (Thiery, 2003). EMT is activated by TGF , FGF, and Notch signaling pathways, which converge to activate transcription factors that subsequently repress the expression of epithelial genes. Key transcription factors in this process include members of the SNAI, Twist, and ZEB families, which suppress epithelial markers and promote expression of mesenchymal markers, hallmarks of the cellular phenotypic switch that occurs in EMT. In addition to enhanced migration, these cells acquire stem cell properties, resistance to apoptosis, undergo cell cycle arrest, and senescence (Vega et al., 2004; Mejlvang et al., 2007; Ansieau et al., 2008; Mani et al., 2008; Sayan et al., 2009). As some features of EMT (such as induction of cell cycle arrest and senescence) are incompatible with successful tumor growth, tumor cells re-acquire epithelial properties when they form secondary tumors through a process recognized as mesenchymal-epithelial transition (MET). In recent years, a growing body of evidence has highlighted the critical role of EMT and its regulation by microRNAs (miRNA) in co-ordinating this complex cellular process.

MiRNAs are 18-24 nucleotides long phylogenetically conserved non-coding RNAs that silence target genes by binding with partial specificity to the $3^{\prime}$ untranslated region ( $3^{\prime}$ UTR) of target mRNA, thus inhibiting translation or promoting mRNA degradation. Their specificity is determined by nucleotides $2-8$ at the $5^{\prime}$ end, termed the miRNA "seed sequence" (Bartel, 2009). To date, more than 1400 human miRNAs have been identified (Sanger miRBase 17; http://www.miRbase.org/index.shtml), forming less than $1 \%$ of all human genes, potentially regulating more than $10 \%$ of all protein coding genes. Crucially, miRNAs can function as both tumor suppressors and oncogenes, and are implicated in promoting EMT and cancer stem cell formation, as well as all other hallmarks of malignancy (Bartels and Tsongalis, 2009).

In light of these recent discoveries, the present article discusses how invasion and EMT pathways are regulated by miRNAs. We have classified key proteins involved in EMT and invasion programs according to their localization (cell membrane, cytoplasm, or nucleus) and point out potential/validated miRNAs regulating their expression and highlight critical knowledge gaps that remain to be addressed to enable improved understanding of the molecular mechanisms behind EMT and metastasis. A list of experimentally validated and in silico identified miRNAs regulating key proteins involved in invasion-metastasis programs can be found in Table 1. We used TargetScan (V 5.2; Lewis et al., 2005), PicTar (Krek et al., 2005), and Microcosm (V 5.0) programs to identify potential miRNAs targeting EMT associated transcripts, and have listed the evolutionary conserved and high scoring ones. 
Table 1 | Predicted/validated microRNAs targeting the expression of invasion/EMT related proteins.

\begin{tabular}{|c|c|c|c|}
\hline Category & $\begin{array}{l}\text { Target } \\
\text { molecule }\end{array}$ & $\begin{array}{l}\text { Validated } \\
\text { miRNAs }\end{array}$ & $\begin{array}{l}\text { Proposed } \\
\text { miRNAs }\end{array}$ \\
\hline $\begin{array}{l}\text { Cell } \\
\text { adhesion }\end{array}$ & E-cadherin & miR-9 & \\
\hline Cell & $\mathrm{N}$-cadherin & & miR-199*, \\
\hline Adhesion & & & $-218^{*}$ \\
\hline Polarity & Par-3 & miR-491-5p & \\
\hline Polarity & Par-4 & miR-451 & miR-2, -304 \\
\hline Cytoplasmic & FAK & miR-138 & \\
\hline Cytoplasmic & Src & miR-205 & miR-9, -132 \\
\hline Cytoplasmic & PTEN & $\begin{array}{l}\text { miR-s-17-92, -26a, } \\
-106 b / 25,-155,-214,-21\end{array}$ & \\
\hline Cytoplasmic & APC & miR-135 & $\begin{array}{l}\operatorname{miR}-27^{*} \\
-153^{*},-125^{*}\end{array}$ \\
\hline $\begin{array}{l}\text { Cytoplasmic/ } \\
\text { nuclear }\end{array}$ & $\beta$-Catenin & miR-200a & miR-320*,-214 \\
\hline Nuclear & ZEB1 & miR-200, miR-205 & \\
\hline Nuclear & ZEB2 & miR-200, miR-205 & miR-153 \\
\hline Nuclear & SNAI1 & miR-204 & $\operatorname{miR}-30^{*},-153$ \\
\hline Nuclear & SNAI2 & miR-124a & miR-10b, -203 \\
\hline Nuclear & TWIST1 & & $\begin{array}{l}\text { miR-33, }-337, \\
-151^{*}\end{array}$ \\
\hline
\end{tabular}

${ }^{*}$ miRNA was identified by multiple algorithms.

\section{CELL ADHESION AND POLARITY PROTEINS CADHERIN SWITCH}

Cell to cell adhesion is an intricately regulated process playing a pivotal role in tumorigenesis. A hallmark of EMT is temporary loss of the epithelial cell-cell adhesion molecule E-cadherin, and concomitant up regulation of $\mathrm{N}$-cadherin; a process termed the cadherin switch (Tomita et al., 2000). The critical nature of the "cadherin switch" in EMT is highlighted by studies demonstrating loss of E-cadherin function alone is sufficient to induce a metastatic cellular phenotype (Perl et al., 1998), although Ecadherin mutations are only observed in gastric and lobular breast cancers (Berx et al., 1998). Regulation of E-cadherin expression is directly mediated by miR- 9 via direct translational inhibition (Ma et al., 2010). In addition, a more complex and indirect regulatory feedback loop modulating E-cadherin expression has been observed between the miR-200 family members (miR-200, miR141, and miR-429), miR-192, miR-205, and the ZEB transcription factors and is discussed later. Acquisition of $\mathrm{N}$-cadherin is also critical for maintenance of a mesenchymal phenotype, but there are limited reports on how $\mathrm{N}$-cadherin transcript is regulated. We have identified miR-199 and 218 as potential regulators of NCadherin translation and are currently investigating this potential regulation.

\section{EPITHELIAL POLARITY}

Another key feature of invasion and EMT is the loss of apicalbasal polarity. Maintenance of cellular polarity is vital to achieve organization of complex epithelial tissues and its loss is a common occurrence in cancer (Royer and Lu, 2011). The critical role of three complexes, namely Scribble, Crumbs, and Par, has been highlighted in maintaining epithelial polarity, of which the Par complex is best understood and implicated in EMT (Zhou et al., 2010; Royer and Lu, 2011). Par-3 depletion disrupts the formation of tight junctions favoring mesenchymal transformation in mammalian cells. Evidence of Par complex regulation by miRNAs comes from studies demonstrating that TGF $\beta$ signaling, a key inducer of EMT, down regulates Par-3 by inducing expression of miR-491-5p in renal tubular epithelial cells (Zhou et al., 2010). Furthermore, Par-4 (also known as LKB1) is regulated by miR-451 and is mutated in one-third of lung adenocarcinomas (Roy et al., 2010). A recent study demonstrated that increased miR-451 expression modulates LKB1/AMPK signaling favoring cellular migration and resistance to apoptosis, and is associated with reduced patient survival (Godlewski et al., 2010). We have identified miR-2 and 304 as potential regulators of Par-4 (Table 1).

\section{CYTOPLASMIC REGULATORS OF EMT}

Within a tissue, cells must adhere not only to one another, but also to the extra-cellular matrix (ECM) that surrounds them. The integrin family of proteins are key regulators of cell-ECM interactions and function as both adhesion molecules and receptors (Dalmay and Edwards, 2006; Parsons et al., 2010). Altered integrin expression is a frequent observation in cancers, particularly at the invasive front, providing evidence of their role as regulators of invasion and EMT. Integrin signaling induces changes in dynamic polymerization of actin cytoskeleton and maintenance of mesenchymal status. Modulation of actin polymerization by miRNAs via integrin signaling and the Rho family of GTPases (Rho, Rac, and CDC42) has been considered in detail in previous reviews and hence is not discussed here (Valastyan and Weinberg, 2011).

Focal adhesion kinase (FAK)-Src complex acts as a sensor to relate the signals from ECM (via integrin engagement) and receptor tyrosine kinases (RTKs) to the cytoskeleton, and plays a complex role in regulating EMT (Avizienyte and Frame, 2005). SrcFAK complex impose multiple pro-metastatic influences, including cadherin switch, lamellipodia formation, and secretion of matrix metalloproteases (Mitra and Schlaepfer, 2006). No miRNAs have been identified to date as direct post-transcriptional repressors of FAKs in the cancer setting however miR-138 was found to regulate FAK protein levels during osteoblast differentiation (Eskildsen et al., 2011). Another developmental study assigned a function of miR-488 as a key regulator of FAKs during differentiation of chondrocytes (Song et al., 2011). Additionally the genomic locus of FAK encodes miR-151, a miRNA that regulates RhoGDIA expression, a GTPase regulatory protein that influences actin polymerization. Expression of FAK results in co-expression of miR-151, which indirectly suppresses FAK mediated signaling cascades involved in cytoskeletal actin polymerization, thus modulating cellular metastatic behavior (Ding et al., 2010). On the other hand, there is only one study assigning a function to a miRNA in controlling Src protein abundance. An inverse correlation has been observed between Src family kinases (SFKs) and miR-205 expression in renal carcinomas and binding of miR-205 to the $3^{\prime}$-UTR of Src mRNA was validated. Over-expression of 
miR-205 resulted in susceptibility to apoptosis, reduced colony formation and invasion, both in vitro and in vivo (Majid et al., 2011).

The Phosphatase and TENsin homolog (PTEN) tumor suppressor gene encodes for a lipid phosphatase and is mutated in varying frequencies in almost all tumors. PTEN suppression contributes to EMT in part by modulation of the Akt/ $\beta$-catenin pathway. $\beta$-Catenin plays a dual role in cellular physiology by forming a core structural component of cadherin junctions and also functions as a transcription factor influencing gene expression. Cytoplasmic $\beta$-catenin is modulated by 3 primary mechanisms, (1) Down regulation of E-cadherin during EMT results in breakdown of cadherin junctions resulting in cytoplasmic and nuclear $\beta$-Catenin accumulation, (2) activated receptor tyrosine kinase signaling suppresses PTEN activity, subsequently activating the Akt/ $\beta$-catenin pathway, and (3) Activation of Wnt/Frizzled signaling removes axin from axin/APC/ $\beta$-catenin/GSK3 $\beta$ complex and inhibits glycogen-synthase kinase (GSK3 $\beta$ ) dependent phosphorylation of $\beta$-catenin, thus promoting its proteosomal degradation Accumulation of $\beta$-catenin in nucleus facilitates gene expression associated with cellular proliferation, transformation, and invasion.

Several miRNAs have been reported to influence tumorigenesis by down regulating PTEN translation, including, miR-17-92 in lymphoproliferative disease (Xiao et al., 2008), miR-19a in leukemia and Cowden's syndrome (Calin et al., 2004; Pezzolesi et al., 2008), miR-26a in high grade glioma (Huse et al., 2009), miR-106b/25 in prostate tumorigenesis (Poliseno et al., 2010a), miR-155 in hepatic carcinogenesis (Wang et al., 2009), miR-214 in ovarian cancer (Yang et al., 2008), and miR-21 in multiple cancers (Krichevsky and Gabriely, 2009). Among these, miR-21 was shown to be upregulated by the potent EMT inducer, TGF $\beta$ (Krichevsky and Gabriely, 2009). Poliseno et al. (2010b) have identified PTENP1, a pseudo-gene that acts as a decoy to PTEN targeting miRNAs, and thus promoting PTEN function. The relevance of this regulatory mechanism in cancer has been further supported by focal loss of the PTENP1 gene in sporadic colorectal cancer (Poliseno et al., 2010b).

Other than PTEN, the mRNAs of the proteins in the axin/APC/ $\beta$-catenin/GSK3 $\beta$ complex are also targeted by miRNAs. MiR-200a takes part in a negative feedback loop with the ZEB family of transcription factors, thus modulating the cadherin complex, and is also involved in direct translational repression of $\beta$-catenin mRNA in meningiomas (Saydam et al., 2009). We also identified miR-320 as a potential regulator of $\beta$-catenin. The miR-135 family target the $3^{\prime}$-UTR of APC mRNA, subsequently increasing Wnt signaling by stabilizing $\beta$-catenin (Nagel et al., 2008). Using at least 2 different algorithms, we noted that the $3^{\prime}$ UTR of APC contains putative binding sites for miR-27, -153 , and -125 .

\section{TRANSCRIPTION FACTORS REGULATING EMT}

The SNAI and ZEB family of transcription factors (Snail, Slug, ZEB1, and ZEB2) are highly conserved zinc finger transcription repressors implicated in embryonic development and tumorigenesis. They bind to E-box like promoter elements in DNA, consequently influencing gene expression. The role of ZEB factors in many human cancers is well-established and corroborates well with the phenotypic switch brought about by E-cadherin loss and other EMT features such as chemoresistance (Browne et al., 2010). In silico analysis of the $3^{\prime}$-UTR region of ZEB family transcripts has revealed 17 conserved miR-200 family binding sites; a finding supported by the well-established role of the miR-200 family in regulating EMT (Burk et al., 2008; Gregory et al., 2008; Korpal et al., 2008; Park et al., 2008). MiR-200-ZEB regulation also stabilizes either the epithelial or mesenchymal phenotype (Brabletz and Brabletz, 2010). During embryogenesis, Slug expression is regulated by miR-124a and over-expression is associated with impaired migration and stem cell formation (Lee et al., 2010). MiR-204 has recently been recognized as a direct post-transcriptional repressor of Snail mRNA and consistent with its postulated tumor suppressive role, was found to be under expressed in different cancer cell lines. Attenuated expression of miR-204 resulted in loss of cell-cell adhesion supporting the EMT related properties of Snail (Wang et al., 2010).

Twist proteins (Twist 1 and 2) are basic Helix-Loop-Helix transcription factors that play an important role in neural crest formation during embryogenesis. Similar to ZEB and the SNAI family, they are potent inducers of EMT and markers of stem cell status. Twist transcription factor over-expression has been reported in multiple solid tumors and is associated with early metastasis and poor clinical outcome (Ansieau et al., 2010). There are no reports proposing a direct post-transcriptional control of TWIST family proteins by a miRNA but we have identified several that may potentially modulate expression of Twist 1 (Table 1).

\section{CONCLUSION}

A better understanding of the complexities of tumor cell invasion, EMT, and MET, are critical for the development of more effective treatments for metastatic cancer. In recent years, a growing number of publications have attested to the link between miRNAs and these mission critical processes during cancer dissemination, and we have summarized many of these in the present manuscript. Given the importance of the process of metastasis in determining cancer specific outcomes, a working knowledge of the miRNAs implicated in these processes is likely to be valuable to all scientists and clinicians dealing with human cancer. We and others consider that acquisition of the migratory properties observed during metastasis requires hierarchical changes in gene expression, some of which are controlled by miRNAs. Here, we have condensed much of this early work, and highlight key deregulated miRNAs targeting molecules involved in cell-cell adhesion, cytoskeletal rearrangement, Wnt signaling, and transcriptional control of EMT. In the future, a more complete dissection of the pathways controlled by these deregulated miRNAs may offer new insights on metastasis, and highlight promising areas for the development of novel anti-cancer therapies.

\section{ACKNOWLEDGMENTS}

We apologize to colleagues whose work we could not cite owing to space limitations. 


\section{REFERENCES}

Ansieau, S., Bastid, J., Doreau, A., Morel, A. P., Bouchet, B. P., Thomas, C., Fauvet, F., Puisieux, I., Doglioni, C., Piccinin, S., Maestro, R., Voeltzel, T., Selmi, A., Valsesia-Wittmann, S., Caron de Fromentel, C., and Puisieux, A. (2008). Induction of EMT by twist proteins as a collateral effect of tumor-promoting inactivation of premature senescence. Cancer Cell 14, 79-89.

Ansieau, S., Morel, A. P., Hinkal, G., Bastid, J., and Puisieux, A. (2010). TWISTing an embryonic transcription factor into an oncoprotein. Oncogene 29, 3173-3184.

Avizienyte, E., and Frame, M. C. (2005). Src and FAK signalling controls adhesion fate and the epithelial-tomesenchymal transition. Curr. Opin. Cell Biol. 17, 542-547.

Bartel, D. P. (2009). MicroRNAs: target recognition and regulatory functions. Cell 136, 215-233.

Bartels, C. L., and Tsongalis, G. J. (2009). MicroRNAs: novel biomarkers for human cancer. Clin. Chem. $55,623-631$.

Berx, G., Becker, K. F., Hofler, H., and van Roy, F. (1998). Mutations of the human E-cadherin (CDH1) gene. Hum. Mutat. 12, 226-237.

Brabletz, S., and Brabletz, T. (2010). The ZEB/miR-200 feedback loop - a motor of cellular plasticity in development and cancer? EMBO Rep. 11, 670-677.

Browne, G., Sayan, A. E., and Tulchinsky, E. (2010). ZEB proteins link cell motility with cell cycle control and cell survival in cancer. Cell Cycle 9, 886-891.

Burk, U., Schubert, J., Wellner, U., Schmalhofer, O., Vincan, E., Spaderna, S., and Brabletz, T. (2008). A reciprocal repression between ZEB1 and members of the miR-200 family promotes EMT and invasion in cancer cells. EMBO Rep. 9, 582-589.

Calin, G. A., Liu, C. G., Sevignani, C., Ferracin, M., Felli, N., Dumitru, C. D., Shimizu, M., Cimmino, A., Zupo, S., Dono, M., Dell'Aquila, M. L., Alder, H., Rassenti, L., Kipps, T. J., Bullrich, F., Negrini, M., and Croce, C. M. (2004). MicroRNA profiling reveals distinct signatures in $\mathrm{B}$ cell chronic lymphocytic leukemias. Proc. Natl. Acad. Sci. U.S.A. 101, 11755-11760.

Dalmay, T., and Edwards, D. R. (2006). MicroRNAs and the hallmarks of cancer. Oncogene 25, 6170-6175.

Ding, J., Huang, S., Wu, S., Zhao, Y., Liang, L., Yan, M., Ge, C., Yao, J., Chen, T., Wan, D., Wang, H.,
Gu, J., Yao, M., Li, J., Tu, H., and He, X. (2010). Gain of miR-151 on chromosome 8q24.3 facilitates tumour cell migration and spreading through downregulating RhoGDIA. Nat. Cell Biol. 12, 390-399.

Eskildsen, T., Taipaleenmaki, H., Stenvang, J., Abdallah, B. M., Ditzel, N., Nossent, A. Y., Bak, M., Kauppinen, S., and Kassem, M. (2011). MicroRNA-138 regulates osteogenic differentiation of human stromal (mesenchymal) stem cells in vivo. Proc. Natl. Acad. Sci. U.S.A. 108, 6139-6144.

Godlewski, J., Nowicki, M. O., Bronisz, A., Nuovo, G., Palatini, J., De Lay, M., Van Brocklyn, J., Ostrowski, M. C., Chiocca, E. A., and Lawler, S. E. (2010). MicroRNA-451 regulates LKB1/AMPK signaling and allows adaptation to metabolic stress in glioma cells. Mol. Cell 37, 620-632.

Gregory, P.A., Bert, A. G., Paterson, E. L. Barry, S. C., Tsykin, A., Farshid, G., Vadas, M. A., Khew-Goodall, Y., and Goodall, G. J. (2008). The miR-200 family and miR-205 regulate epithelial to mesenchymal transition by targeting ZEB1 and SIP1. Nat. Cell Biol. 10, 593-601.

Huse, J. T., Brennan, C., Hambardzumyan, D., Wee, B., Pena, J., Rouhanifard, S. H., Sohn-Lee, C., le Sage, C., Agami, R., Tuschl, T., and Holland, E. C. (2009). The PTENregulating microRNA miR-26a is amplified in high-grade glioma and facilitates gliomagenesis in vivo. Genes Dev. 23, 1327-1337.

Jemal, A., Bray, F., Center, M. M., Ferlay, J., Ward, E., and Forman, D. (2011). Global cancer statistics. CA Cancer J. Clin. 61, 69-90.

Korpal, M., Lee, E. S., Hu, G., and Kang, Y. (2008). The miR-200 family inhibits epithelial-mesenchymal transition and cancer cell migration by direct targeting of Ecadherin transcriptional repressors ZEB1 and ZEB2. J. Biol. Chem. 283, 14910-14914.

Krek, A., Grun, D., Poy, M. N., Wolf, R., Rosenberg, L., Epstein, E. J., MacMenamin, P., da Piedade, I., Gunsalus, K. C., Stoffel, M., and Rajewsky, N. (2005). Combinatorial microRNA target predictions. Nat. Genet. 37, 495-500.

Krichevsky, A. M., and Gabriely, G. (2009). miR-21: a small multifaceted RNA. J. Cell. Mol. Med. 13, 39-53.

Lee, M. R., Kim, J. S., and Kim, K. S. (2010). miR-124a is important for migratory cell fate transition during gastrulation of human embryonic stem cells. Stem Cells 28, 1550-1559.
Lewis, B. P., Burge, C. B., and Bartel D. P. (2005). Conserved seed pairing, often flanked by adenosines, indicates that thousands of human genes are microRNA targets. Cell 120, 15-20.

Ma, L., Young, J., Prabhala, H., Pan, E., Mestdagh, P., Muth, D., TeruyaFeldstein, J., Reinhardt, F., Onder, T. T., Valastyan, S., Westermann, F., Speleman, F., Vandesompele, J., and Weinberg, R. A. (2010). miR-9, a MYC/MYCN-activated microRNA, regulates E-cadherin and cancer metastasis. Nat. Cell Biol. 12, 247-256.

Majid, S., Saini, S., Dar, A. A., Hirata H., Shahryari, V., Tanaka, Y., Yamamura, S., Ueno, K., Zaman, M. S., Singh, K., Chang, I., Deng, G. and Dahiya, R. (2011). MicroRNA205 inhibits Src-mediated oncogenic pathways in renal cancer. Cancer Res. 71, 2611-2621.

Mani, S. A., Guo, W., Liao, M. J. Eaton, E. N., Ayyanan, A., Zhou, A. Y., Brooks, M., Reinhard, F. Zhang, C. C., Shipitsin, M., Campbell, L. L., Polyak, K., Brisken, C., Yang, J., and Weinberg, R. A. (2008). The epithelial-mesenchymal transition generates cells with properties of stem cells. Cell 133, 704-715.

Mejlvang, J., Kriajevska, M., Vandewalle, C., Chernova, T., Sayan, A. E., Berx G., Mellon, J. K., and Tulchinsky, E. (2007). Direct repression of cyclin D1 by SIP1 attenuates cell cycle progression in cells undergoing an epithelial mesenchymal transition. Mol. Biol. Cell 18, 4615-4624.

Mitra, S. K., and Schlaepfer, D. D. (2006). Integrin-regulated FAK-Src signaling in normal and cancer cells. Curr. Opin. Cell Biol. 18, 516-523.

Nagel, R., le Sage, C., Diosdado, B., van der Waal, M., Oude Vrielink, J. A., Bolijn, A., Meijer, G. A., and Agami, R. (2008). Regulation of the adenomatous polyposis coli gene by the miR-135 family in colorectal cancer. Cancer Res. 68, 5795-5802.

Park, S. M., Gaur, A. B., Lengyel, E., and Peter, M. E. (2008). The miR200 family determines the epithelial phenotype of cancer cells by targeting the E-cadherin repressors ZEB1 and ZEB2. Genes Dev. 22, 894-907.

Parsons, J. T., Horwitz, A. R., and Schwartz, M. A. (2010). Cell adhesion: integrating cytoskeletal dynamics and cellular tension. Nat. Rev. Mol. Cell Biol. 11, 633-643.

Perl, A. K., Wilgenbus, P., Dahl, U., Semb, H., and Christofori, G. (1998). A causal role for E-cadherin in the transition from adenoma to carcinoma. Nature 392, 190-193.
Pezzolesi, M. G., Platzer, P., Waite, K. A., and Eng, C. (2008). Differential expression of PTEN-targeting microRNAs miR-19a and miR-21 in Cowden syndrome. Am. J. Hum. Genet. 82, 1141-1149.

Poliseno, L., Salmena, L., Riccardi, L., Fornari, A., Song, M. S., Hobbs, R. M., Sportoletti, P., Varmeh, S., Egia, A., Fedele, G., Rameh, L., Loda, M., and Pandolfi, P. P. (2010a). Identification of the miR-106b 25 microRNA cluster as a protooncogenic PTEN-targeting intron that cooperates with its host gene MCM7 in transformation. Sci. Signal. 3, ra29.

Poliseno, L., Salmena, L., Zhang, J., Carver, B., Haveman, W. J., and Pandolfi, P. P. (2010b). A coding-independent function of gene and pseudogene mRNAs regulates tumour biology. Nature 465 , 1033-1038.

Roy, B. C., Kohno, T., Iwakawa, R., Moriguchi, T., Kiyono, T., Morishita, K., Sanchez-Cespedes, M., Akiyama, T., and Yokota, J. (2010). Involvement of LKB1 in epithelialmesenchymal transition (EMT) of human lung cancer cells. Lung Cancer 70, 136-145.

Royer, C., and Lu, X. (2011). Epithelial cell polarity: a major gatekeeper against cancer? Cell Death Differ. 18 1470-1477.

Sayan, A. E., Griffiths, T. R., Pal, R., Browne, G. J., Ruddick, A., Yagci, T., Edwards, R., Mayer, N. J., Qazi, H., Goyal, S., Fernandez, S., Straatman, K., Jones, G. D., Bowman, K. J., Colquhoun, A., Mellon, J. K., Kriajevska, M., and Tulchinsky, E. (2009). SIP1 protein protects cells from DNA damage-induced apoptosis and has independent prognostic value in bladder cancer. Proc. Natl. Acad. Sci. U.S.A. 106, 14884-14889.

Saydam, O., Shen, Y., Wurdinger, T., Senol, O., Boke, E., James, M. F., Tannous, B. A., StemmerRachamimov, A. O., Yi, M., Stephens, R. M., Fraefel, C., Gusella, J. F., Krichevsky, A. M., and Breakefield, X. O. (2009). Downregulated microRNA-200a in meningiomas promotes tumor growth by reducing E-cadherin and activating the Wnt/beta-catenin signaling pathway. Mol. Cell. Biol. 29, 5923-5940.

Song, J., Kim, D., and Jin, E. J. (2011). MicroRNA-488 suppresses cell migration through modulation of the focal adhesion activity during chondrogenic differentiation of chick limb mesenchymal cells. Cell Biol. Int. 35, 179-185. 
Thiery, J. P. (2003). Epithelialmesenchymal transitions in development and pathologies. Curr. Opin. Cell Biol. 15, 740-746.

Thiery, J. P., and Sleeman, J. P. (2006). Complex networks orchestrate epithelial-mesenchymal transitions. Nat. Rev. Mol. Cell Biol. 7, 131-142.

Tomita, K., van Bokhoven, A., van Leenders, G. J., Ruijter, E. T., Jansen, C. F., Bussemakers, M. J., and Schalken, J. A. (2000). Cadherin switching in human prostate cancer progression. Cancer Res. 60, 3650-3654.

Valastyan, S., and Weinberg, R. A. (2011). Roles for microRNAs in the regulation of cell adhesion molecules. J. Cell Sci. 124(Pt 7), 999-1006.

Vega, S., Morales, A. V., Ocana, O. H., Valdes, F., Fabregat, I., and Nieto, M. A. (2004). Snail blocks the cell cycle and confers resistance to cell death. Genes Dev. 18, 1131-1143.

Wang, B., Majumder, S., Nuovo, G., Kutay, H., Volinia, S., Patel, T., Schmittgen, T. D., Croce, C., Ghoshal, K., and Jacob, S. T. (2009). Role of microRNA-155 at early stages of hepatocarcinogenesis induced by choline-deficient and amino acid-defined diet in C57BL/6 mice. Hepatology 50, 1152-1161.

Wang, F. E., Zhang, C., Maminishkis, A., Dong, L., Zhi, C., Li, R., Zhao, J., Majerciak, V., Gaur, A. B., Chen, S., and Miller, S. S. (2010). MicroRNA204/211 alters epithelial physiology. FASEB J. 24, 1552-1571.

Xiao, C., Srinivasan, L., Calado, D. P., Patterson, H. C., Zhang, B., Wang, J., Henderson, J. M., Kutok, J. L., and Rajewsky, K. (2008). Lymphoproliferative disease and autoimmunity in mice with increased miR-17-92 expression in lymphocytes. Nat. Immunol. 9, 405-414.

Yang, H., Kong, W., He, L., Zhao, J. J., O’Donnell, J. D., Wang, J., Wenham, R. M., Coppola, D., Kruk, P. A., Nicosia, S. V., and Cheng, J. Q. (2008). MicroRNA expression profiling in human ovarian cancer: miR-214 induces cell survival and cisplatin resistance by targeting PTEN. Cancer Res. 68, 425-433.

Zhou, Q., Fan, J., Ding, X., Peng, W., Yu, X., Chen, Y., and Nie, J. (2010). TGF\{beta\}-induced MiR-491-5p expression promotes Par-3 degradation in rat proximal tubular epithelial cells. J. Biol. Chem. 285, 40019-40027.

Conflict of Interest Statement: The authors declare that the research was conducted in the absence of any commercial or financial relationships that could be construed as a potential conflict of interest.

Received: 16 August 2011; accepted: 16 August 2011; published online: 05 September 2011

Citation: Sreekumar $R$, Sayan BS, Mirnezami AH and Sayan AE (2011) MicroRNA control of invasion and metastasis pathways. Front. Gene. 2:58. doi: 10.3389/fgene.2011.00058

This article was submitted to Frontiers in Non-Coding RNA, a specialty of Frontiers in Genetics.

Copyright (C) 2011 Sreekumar, Sayan, Mirnezami and Sayan. This is an openaccess article subject to a non-exclusive license between the authors and Frontiers Media SA, which permits use, distribution and reproduction in other forums, provided the original authors and source are credited and other Frontiers conditions are complied with. 